\title{
REAL GAS CFD SIMULATIONS OF HYDROGEN/OXYGEN SUPERCRITICAL COMBUSTION
}

\author{
S. Pohl ${ }^{1}$, M. Jarczyk ${ }^{1}$, M. Pfitzner ${ }^{1}$, and B. Rogg ${ }^{2}$ \\ ${ }^{1}$ Institute for Thermodynamics, Universität der Bundeswehr München \\ Werner-Heisenberg-Weg 39, Neubiberg 85577, Germany \\ ${ }^{2}$ Institute for Thermo- and Fluiddynamics, Ruhr-Universität Bochum \\ Universitätsstrasse 150, Bochum 44780, Germany
}

A comprehensive numerical framework has been established to simulate reacting flows under conditions typically encountered in rocket combustion chambers. The model implemented into the commercial CFD Code ANSYS CFX includes appropriate real gas relations based on the volume-corrected Peng-Robinson (PR) equation of state (EOS) for the flow field and a real gas extension of the laminar flamelet combustion model. The results indicate that the real gas relations have a considerably larger impact on the flow field than on the detailed flame structure. Generally, a realistic flame shape could be achieved for the real gas approach compared to experimental data from the Mascotte test rig V03 operated at ONERA when the differential diffusion processes were only considered within the flame zone.

\section{INTRODUCTION}

Modern high performance rocket combustion engines, as well as the first-stage engine of the Ariane 5, Vulcain II, are run at high pressures up to 100 bar while the propellants, usually hydrogen and oxygen, are injected at very low temperatures. For hydrogen, the pressure and the temperature in the combustion chamber are supercritical, whereas for oxygen, only the pressure is above its critical value. The injection temperature, however, is often significantly lower than the critical temperature of oxygen $\left(T_{\text {crit }, \mathrm{O}_{2}}=154.6 \mathrm{~K}\right)$. Under such conditions

This is an Open Access article distributed under the terms of the Creative Commons Attribution License 2.0, which permits unrestricted use, distribution, and reproduction in any medium, provided the original work is properly cited. 
the mean free path between the molecules in the fluid becomes small enough to allow molecular interactions to become important. This leads to significant deviations from the ideal gas assumption, which entirely neglects intermolecular attraction and repulsion effects. For this reason, proper real gas relations for thermodynamic and transport properties as well as for the combustion model need to be incorporated into a computational fluid dynamics (CFD) simulation.

A very common method in modeling turbulent combustion is the flamelet approach developed by Peters [1] which is based on the solution of a counterflow diffusion flame. Due to the one-dimensional (1D) character of this configuration, the resulting flame structures and extinction rates can be assessed without much effort and detailed chemical kinetics can be considered decoupled from the flow field. Thus, the laminar flamelet combustion model is often applied in order to simulate reacting flows of industrial interest.

Several analyses of counterflow diffusion flames have been performed focusing on low as well as on high pressure conditions. It was found that the pressure as well as the strain rate have a significant effect on the flame structure and the flame extinction [2]. The analysis of nonpremixed strained flames at different pressures performed by Pons et al. [3] indicates that the flame thickness is inversely proportional to the square root of pressure. Likewise, transcritical injection conditions for oxygen/methane flames were studied by Pons et al. [4] using the PR EOS. Balakrishnan et al. [5] examined flame structures, extinction and ignition limits for $\mathrm{H}_{2}$ /air flames for detailed and reduced chemical reaction mechanisms. For these propellants, thermal diffusion was found to be an important effect.

Intensive research has been done in recent years to simulate reacting and nonreacting flows under trans- and supercritical conditions. Reynolds-averaged Navier-Stokes (RANS) simulations, for example, were performed in order to simulate the injection and combustion of gaseous hydrogen cryogenic liquid oxygen (LOx) at supercritical pressures [6-10]. Here, real gas relations based on the volume-corrected PR EOS were considered by Poschner and Pfitzner $[6,7]$ for the flow field, whereas for the combustion, the standard laminar flamelet model available in the commercial CFD code ANSYS CFX was used. A modified Soave-Redlich-Kwong EOS and consistent real gas thermodynamics were applied along with a real fluid flamelet model formulated in mixture fraction space by Kim et al. $[9,10]$. The results indicate that the real gas approach does not affect the flamelet structure significantly. A validation against experimental data available for the Mascotte C60 case shows a good agreement for the flame spreading angle and the flame location. As typically applied in turbulent combustion modeling the real gas flamelet library in this case assumes equal diffusivities for all species considered in the reaction. The consideration of the molecular transport, however, failed in predicting the experimental results for turbulent $\mathrm{CO} / \mathrm{H}_{2} / \mathrm{N}_{2}$ jet flames [11]. Thus, Barlow et al. [11] concluded 
that turbulent stirring has a greater effect on the turbulent flame structure than molecular diffusion.

A modified Soave-Redlich-Kwong EOS and consistent real gas thermodynamics were also used by Ribert et al. [12] who studied counterflow diffusion flames in the physical space over the entire regime of thermodynamic states. Significant real gas effects due to steep property variations were found in the transcritical regime. The resulting influence on the flame structure, however, seems to be limited since the oxygen heats up very rapidly and behaves like an ideal gas when entering the flame zone. Based on this framework, a flamelet library has been generated and applied along with a Large Eddy Simulation (LES) formulation for the turbulence closure for $\mathrm{LOx} /$ methane flames at supercritical pressures [13]. The laminar flamelet model was found here to be an appropriate choice for the considered testing conditions.

Further large eddy simulations of reacting and nonreacting supercritical jets were performed by Zong and Yang [14], Schmitt et al. [15-17] and Matsuyama et al. [18] as well as by Jarczyk and Pfitzner [19], Petit et al. [20] and the group around Menon [21]. The laminar flamelet model was used, e.g., by Matsuyama et al. [18] to validate the simulation results against experimental test data obtained at the P8 combustor at the DLR for supercritical pressures. Other configurations such as shear layers were also analyzed in great detail, for example, by the research group of Bellan [22]. Here, the study focused on the temporal development of $\mathrm{H}_{2} / \mathrm{O}_{2}$ shears layers under supercritical conditions applying the direct numerical simulation technique.

Detailed investigations of the mixing and the combustion process of cryogenic oxygen-hydrogen coaxial jet flames at supercritical pressure were also performed by Oefelein [23] using LES and direct numerical simulation (DNS) techniques. Special emphasis was placed on the various diffusion mechanisms of which crossdiffusions terms like Soret and Dufour effects were found to be negligible close to the injector, while the ordinary (mass) diffusion terms are of crucial importance. Oefelein concluded that a diffusion dominated combustion mode is present in this region.

Within the present study, the work performed by Poschner and Pfitzner $[6,7]$ is extended in order to consistently include real gas relations for the flow field and the combustion model within a CFD simulation. For this purpose, the influence of real gas effects on the local structure of $\mathrm{H}_{2} / \mathrm{O}_{2}$ counterflow diffusion flames is investigated at supercritical pressures and very low propellant temperatures using the combustion simulation laboratory COSILAB [24]. Based on this framework, real gas flamelet libraries are generated and applied along with the laminar flamelet combustion model available in the commercial CFD code ANSYS CFX. The established model is finally validated against experimental data from the Mascotte test rig operated at ONERA for a gaseous hydrogen cryogenic liquid oxygen jet flame. 


\section{THEORETICAL FORMULATION}

\subsection{Real Gas Counterflow Diffusion Flames}

The physical configuration employed within this study is the axisymmetric counterflow flame shown schematically in Fig. 1. Two opposing jets of fuel and oxidizer create a stagnation plane with a laminar diffusion flame stabilized at the location of the stoichiometric mixture fraction. To ensure a reliable prediction of the flame behavior over the entire regime of thermodynamic states, the basic governing equations are extended by a real gas EOS with appropriate thermodynamic relations and property evaluation schemes.

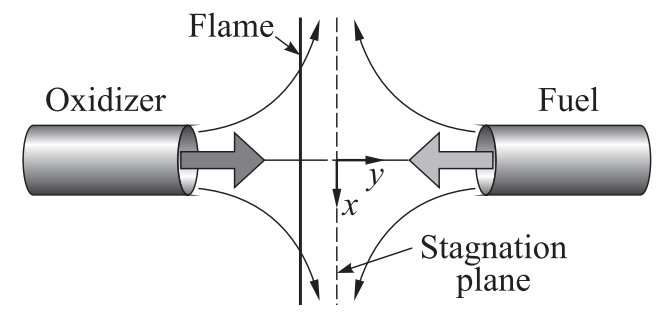

Figure 1 A schematic view of a counterflow diffusion flame configuration

\subsubsection{Governing equations}

Along the axis of symmetry, the 1D balance equations for mass:

$$
\frac{\partial \rho}{\partial t}=-\frac{\partial(\rho v)}{\partial y}-2 \rho G
$$

radial momentum:

$$
\rho \frac{\partial G}{\partial t}=\frac{\partial}{\partial y}\left(\mu \frac{\partial G}{\partial y}\right)-\rho v \frac{\partial G}{\partial y}-\rho G^{2}+\rho_{+\infty} a_{s}^{2} ;
$$

species mass fraction:

$$
\rho \frac{\partial Y_{i}}{\partial t}=-\rho v \frac{\partial Y_{i}}{\partial y}-\frac{\partial}{\partial y}\left(\rho V_{i} Y_{i}\right)+\dot{\omega}_{i}
$$

and energy:

$$
\rho c_{p} \frac{\partial T}{\partial t}=\frac{\partial}{\partial y}\left(\lambda \frac{\partial T}{\partial y}\right)-\rho v c_{p} \frac{\partial T}{\partial y}-\rho \sum_{i=1}^{I} Y_{i} V_{i} \frac{\partial h_{i}}{\partial y}-\sum_{i=1}^{I} h_{i} \dot{\omega}_{i}
$$

which are solved by COSILAB are given in physical coordinates $x, y$ [24]. 
The similarity transformation described in [24] was used here to derive Eqs. (1)-(4) and Eq. (5) below. The quantity $G$ is defined as $G=u / x$ with the velocity components $u, v$ in $x$ and $y$ direction, respectively. $a_{s}\left[s^{-1}\right]$ is the prescribed constant strainrate at the fuel boundary. It varies throughout the computational domain. It can be used to generate all flow conditions from the nearly strain free case up to the flame extinction. The parameters $\rho, T, \mu$, and $\lambda$ are the mixture density, temperature, dynamic viscosity, and thermal conductivity, respectively, whereas $Y_{i}$ denotes the species mass fractions. The evaluation of the species partial specific enthalpy $h_{i}$ and the mixture heat capacity $c_{p}$ is described in the following paragraph. $\dot{\omega}_{i}$ is the net mass rate of production of the $i$ th species.

The species diffusion velocity $V_{i}$ is composed of three parts, the ordinary diffusion velocity $V_{i}{ }^{D}$, the thermal diffusion velocity $V_{i}^{T}$, considered for light species $H$ and $H_{2}$, and a correction velocity $V_{c}$ [24] to ensure that the net species diffusion flux is zero:

$$
V_{i}=V_{i}^{D}+V_{i}^{T}+V_{c}=-\frac{D_{i, m}}{X_{i}} \frac{\partial X_{i}}{\partial y}-\frac{D_{i, m} \theta_{i}}{X_{i} T} \frac{\partial T}{\partial y}-\sum_{i=1}^{I} Y_{i}\left(V_{i}^{D}+V_{i}^{T}\right) .
$$

Here, $X_{i}$ denotes the species mole fractions, $D_{i, m}$ the mixture averaged diffusion coefficient, and thermal diffusion ratio $\theta_{i}$ is calculated according to Chapman and Cowling [25] as given in [26].

In order to generate flamelet libraries, an additional transport equation is solved for the mixture fraction $Z$ :

$$
\rho \frac{\partial Z}{\partial t}=\frac{\partial}{\partial y}\left(\rho D_{Z} \frac{\partial Z}{\partial y}\right)-\rho v \frac{\partial Z}{\partial y} .
$$

With the definition of the Lewis number as ratio of thermal to mass diffusivity, the mixture fraction diffusion coefficient $D_{Z}$ is typically chosen in such a way that the Lewis number of the mixture fraction is equal to unity $\left(\operatorname{Le}_{Z}=1\right)$ [27]:

$$
\mathrm{Le}_{i}=\frac{\lambda}{\rho c_{p} D_{i}} .
$$

\subsubsection{Thermodynamic properties and equation of state}

The thermodynamic properties such as the species partial specific enthalpy can be calculated from the chemical potential $\mu_{i}$ as follows:

$$
h_{i}\left(T, p, X_{i}\right)=-\frac{T^{2}}{M_{i}}\left(\frac{\partial\left(\mu_{i} / T\right)}{\partial T}\right)_{p, X_{i}} .
$$


Here, $\mu_{i}$ is defined as $\mu_{i}\left(T, p, X_{i}\right)=G_{0 i}^{0}(T)+R_{m} T \ln \left(p / p_{0}\right)+R_{m} T \ln \left(x_{i} \varphi_{i}\right)$ where $G_{0 i}^{0}$ is the ideal gas Gibbs free enthalpy of the $i$ th species at the reference pressure and $\varphi_{i}$ is the fugacity coefficient.

The internal energy as well as the constant pressure specific heat capacity are calculated as the sum of an ideal reference value and a departure function accounting for real gas effects:

$$
c_{p}\left(T, V_{m}\right)=c_{V}\left(T, V_{m}\right)-T \frac{(\partial p / \partial T)_{V_{m}}^{2}}{\left(\partial p / \partial V_{m}\right)_{T}} .
$$

The constant volume specific heat capacity is defined as $c_{V}\left(T, V_{m}\right)=(\partial u / \partial T)_{V_{m}}$ and the internal energy is derived from

$$
u\left(T, V_{m}\right)=u_{0}(T)+\int_{V_{m}}^{V_{\infty}}\left[p-T\left(\frac{\partial p}{\partial T}\right)_{V_{m}}\right] d V_{m}
$$

Here, the subscript 0 refers to the ideal reference state at low pressure which is evaluated from the NASA polynomials [28]. The departure functions on the right hand side of Eqs. (8) and (9) have to be determined using an appropriate EOS. As the PR equation [29] is known to be not very accurate in predicting the density in transcritical regions, an additional volume-correction method established by Harstad et al. [30] has been applied within the present work:

$$
p=\frac{R T}{V_{m}-b}-\frac{a(T)}{V_{m}^{2}+2 V_{m} b-b^{2}} .
$$

Here, $V_{m}$ is the molar volume and $R=8.314472 \mathrm{~J} /(\mathrm{mol} \cdot \mathrm{K})$ is the universal gas constant. The constants $a(T)$ and $b$ are calculated from empirical relations. The constant $a(T)$ accounts for attractive forces between the molecules in the fluid and is defined as $a(T)=a_{0} \alpha(T)$. The constant $a_{0}$ is calculated from the relation $a_{0}=0.457235 R^{2} T_{c}^{2} / p_{c}$ and the temperature dependent function is given by

$$
\alpha(T)=\left(1+\gamma\left(1-\sqrt{\frac{T}{T_{c}}}\right)\right)^{2}
$$

where $\gamma=0.37464+1.54226 \omega-0.26992 \omega^{2}$ is the function of the acentric factor $\omega$. The effects of the reduction of the free volume by the particular volume of the molecules is taken into account by $b=0.077796 R T_{c} / p_{c}$. For the critical points of all substances, the values published by Ribert et al. [12] have been applied. They are summarized in Table 1 .

Real gas phenomena also have to be considered in the mixing process of pure components. For this purpose, an extended corresponding states principle has 
been applied in the present study. The multicomponent mixture is assumed to behave like a pure real gas component but with coefficients $a$ and $b$ in the EOS modified appropriately through mixing rules. The mixture properties are also calculated using the PR EOS with parameters calculated from real gas mixing rules. Here, the van der Waals mixing rules [31] have been applied. The binary interaction parameters $k_{i j}$ are set to zero as there were no values available:

$$
\begin{aligned}
a & =\sum_{i} \sum_{j} X_{i} X_{j} \sqrt{a_{i} a_{j}}\left(1-k_{i j}\right) ; \\
b & =\sum_{i} X_{i} b_{i} .
\end{aligned}
$$

Table 1 Critical points of all species occurring during the combustion of $\mathrm{H}_{2}$ and $\mathrm{O}_{2}$ [12]

\begin{tabular}{lrc}
\hline Species & $T_{c}, \mathrm{~K}$ & $p_{c}$, bar \\
\hline $\mathrm{H}_{2}$ & 33.2 & 13 \\
$\mathrm{O}_{2}$ & 154.6 & 50.4 \\
$\mathrm{H}$ & 404.3 & 88.2 \\
$\mathrm{O}$ & 367.4 & 76 \\
$\mathrm{OH}$ & 443.7 & 85.4 \\
$\mathrm{HO}_{2}$ & 487.3 & 82.8 \\
$\mathrm{H}_{2} \mathrm{O}$ & 647.3 & 221.2 \\
$\mathrm{H}_{2} \mathrm{O}_{2}$ & 544.3 & 93.5 \\
\hline
\end{tabular}

A comprehensive validation of the real gas relations summarized above has been perfomed by Poschner and Pfitzner [6, 7] in their previous works.

\subsubsection{Transport properties}

Close to the critical point, small changes of state evoke strong variations of the transport properties in such a way that the quantities like the thermal conductivity and the dynamic viscosity experience steep gradients. For this reason, an accurate evaluation of the transport properties for both the pure components and the mixture is of vital importance for a reliable prediction of real gas flows. Within this work, the dynamic viscosity $\eta$ as well as the thermal conductivity $\lambda$ are estimated based on the approach established by Chung et al. [32]. Here, the dynamic viscosity for dilute gases $\eta_{0}$ is approximated as

$$
\eta_{0}=4.0785 \cdot 10^{-5} \frac{(M T)^{1 / 2}}{V_{c}^{2 / 3} \Omega^{*}} F_{c}
$$

where $V_{c}$ is the critical molar volume; $T$ is the temperature; and $M$ is the molecular weight. The correction factor $F_{c}$ accounts for the polyatomic molecular structure of the fluid while $\Omega^{*}$ is the reduced collision integral. For dense fluids, Eq. (10) is extended to the following correlation including the effects of the temperature (index $k$ ) and the pressure (index $p$ ):

$$
\eta=\eta_{k}+\eta_{p}
$$

with $\eta_{p}=\left(36.344 \cdot 10^{-6}\left(M T_{c}\right)^{1 / 2} / V_{c}^{2 / 3}\right) A_{7} y^{2} G_{2} \exp \left(A_{8}+A_{9} / T^{*}+A_{10} / T^{* 2}\right)$ and $\eta_{k}=\eta_{0}\left[1 / G_{2}+A_{6} y\right]$. This model has been validated for pressures up to 
3447 bar and temperatures ranging from 70 to $973 \mathrm{~K}$. All parameters which are not explicitly given here are calculated as described in [32].

Similarly to the dynamic viscosity, the thermal conductivity for dense fluids is evaluated from

$$
\lambda=\lambda_{k}+\lambda_{p}
$$

Here, the temperature effects are taken into account by $\lambda_{k}=\lambda_{0}\left[1 / H_{2}+B_{6} y\right]$ and the pressure effects are given as $\lambda_{p}=\left(3.039 \cdot 10^{-4}\left(T_{c} / M\right)^{1 / 2} / V_{c}^{2 / 3}\right) B_{7} y^{2} H_{2} T_{r}^{1 / 2}$ where $T_{c}$ denotes the critical and $T_{r}$ the reduced temperature. The thermal conductivity for dilute gases $\lambda_{0}$ is estimated from the following equation with the correlation $\Psi$ as given by Chung et al. [32]:

$$
\lambda_{0}=7.452 \frac{\eta_{0}}{M} \Psi
$$

This method has been validated for pressures up to 1247 bar and temperatures from 80 to $973 \mathrm{~K}$. For both properties, the appropriate mixing rules recommended by Chung et al. [32] have been applied.

For the binary diffusion coefficients, the approach proposed by Fuller et al. [33] is used as given in [31]:

$$
D_{i j}=\frac{0.00143 T^{1.75}}{p M_{i j}^{1 / 2}\left[\left(\Sigma_{v}\right)_{i}^{1 / 3}+\left(\Sigma_{v}\right)_{j}^{1 / 3}\right]^{2}} .
$$

Here, $M_{i j}$ can be calculated from $M_{i j}=2 /\left[\left(1 / M_{i}\right)+\left(1 / M_{j}\right)\right]$ and $\Sigma_{v}$ is the sum of the atomic diffusion volumes for each component. The mixture averaged diffusion coefficient of one component into the mixture is estimated using Bird's law given in [26]. To circumvent mathematical difficulties in the limit of the mixture becoming a pure species, the following equation is applied along with adding a small number $\delta=10^{-12}$ to all species mole fractions. $\bar{M}$ denotes the mean molar mass of all species:

$$
D_{i, m}=\frac{\sum_{j=1, j \neq i}^{n}\left(X_{j} M_{j}\right)}{\bar{M} \sum_{j=1, j \neq i}^{n}\left(X_{j} / D_{i j}\right)} .
$$

Pressure effects are taken into account by the approach recommended by Takahashi [34]. Here, $(D p)_{R}$ is the ratio of the product of diffusion coefficient $D$ and pressure $p$ to its value at low pressures $(D p)_{R}=(D p) /(D p)_{0}$. The index $r$ indicates reduced quantities. Model uncertainties may arise when the reduced temperature of the mixture is smaller than unity [12]:

$$
\frac{(D p)_{R}}{(D p)_{R, l}}=f\left(T_{r}, p_{r}\right) \text {. }
$$


The species diffusion caused by a temperature gradient (Soret-effect) is taken into account as described in $[24,26]$ for the light species $\mathrm{H}$ and $\mathrm{H}_{2}$. Again, $\theta_{i}$ denotes the thermal diffusion ratio which is given in [25]. Heat diffusion due to concentration gradients (Dufour-effect), however, is neglected in this study:

$$
D_{i}^{T}=\rho \frac{Y_{i}}{X_{i}} D_{i, m} \theta_{i}
$$

\subsubsection{Boundary conditions and numerical method}

The general boundary conditions which are applied in COSILAB for a counterflow diffusion flame problem formulated in a stagnation point flow are listed in Table 2 [24]. The stagnation plane is defined by $v_{y=0}=0$.

Table 2 Boundary conditions used in COSILAB

\begin{tabular}{cccc}
\hline Boundary condition & $G / a_{s}$ & $T$ & $Y$ \\
\hline$y=-\infty$ & $\left(\rho_{+\infty} / \rho_{-\infty}\right)^{1 / 2}$ & $T_{-\infty}$ & $Y_{-\infty}$ \\
$y=+\infty$ & 1 & $T_{+\infty}$ & $Y_{+\infty}$ \\
\hline
\end{tabular}

The governing equations presented here, subject to the above boundary conditions, are discretized on a mesh of grid points, and the resulting system of nonlinear equations is then solved by the optimized, mixed transient-steady Newton's method to arrive at a steady-state solution. In particular, in applying Newton's method, a damping strategy is employed which allows the Jacobians to be re-evaluated only periodically. To resolve the local gradients of the dependent variables accurately, self-adaptive gridding is implemented into the numerical procedure. For a more detailed description of the numerical method, Ref. [24] should be consulted.

\subsection{The Flamelet Model and Its Application in Turbulent Combustion Simulations}

In the laminar flamelet model available in ANSYS CFX, the species mean mass fractions are stored in the flamelet library as a function of the mean mixture fractions $\widetilde{Z}$, its variance $\widetilde{Z^{\prime \prime 2}}$, and the scalar dissipation rate evaluated at stoichiometric conditions $\widetilde{\chi_{\mathrm{st}}}$. They can therefore be calculated by weighting the flamelet solution with a probability density function (pdf) $\widetilde{P}$ and integration of the result as follows [35]:

$$
\widetilde{Y}_{i}=\int_{0}^{1} Y_{i}\left(Z, \widetilde{\chi_{\mathrm{st}}}\right) \widetilde{P}(Z) d Z=\int_{0}^{1} Y_{i}\left(Z, \widetilde{\chi_{\mathrm{st}}}\right) \frac{Z^{a-1}(1-Z)^{b-1}}{\int_{0}^{1} Z^{a-1}(1-Z)^{b-1} d Z} d Z
$$


As shown here, typically, a $\beta$-function is used as the pdf of the mixture fraction. The parameters $a$ and $b$ are estimated from $a=\widetilde{Z} g$ and $b=(1-\widetilde{Z}) g$ where $g=\widetilde{Z}(1-\widetilde{Z}) / \widetilde{Z^{\prime \prime 2}}-1$. Different shapes including singularities at one or even both end points of the mixture fraction range can be reproduced by the $\beta$-pdf. To deal with the numerical difficulties arising from the singularities, the method proposed by Liu et al. [36] has been applied. The pdf of the scalar dissipation rate is taken here as the delta function at the conditional Favre mean value $\widetilde{\chi_{\mathrm{st}}}$. In CFX, the temperature is not included in the flamelet library but evaluated within the CFD code from the mixture enthalpy.

In order to couple the laminar flamelet solution with the turbulent flow field, the set of Favre-averaged governing equations including mass, momentum and enthalpy has to be supplemented by adding the transport equations for the mean mixture fraction $\widetilde{Z}$ and its variance $\widetilde{Z^{\prime \prime 2}}[35]$. The system of equations has to be closed then by applying a suitable turbulence model:

$$
\begin{aligned}
& \frac{\partial(\bar{\rho} \widetilde{Z})}{\partial t}+\frac{\partial\left(\overline{\rho u_{j}} \widetilde{Z}\right)}{\partial x_{j}}=\frac{\partial}{\partial x_{j}}\left\{\left(\bar{\eta}+\frac{\eta_{t}}{\sigma_{Z}}\right) \frac{\partial \widetilde{Z}}{\partial x_{j}}\right\} ; \\
& \frac{\partial\left(\bar{\rho} \widetilde{Z^{\prime \prime 2}}\right)}{\partial t}+\frac{\partial\left(\overline{\rho u_{j}} \widetilde{Z^{\prime \prime 2}}\right)}{\partial x_{j}}=-\bar{\rho} \tilde{\chi}+\frac{\partial}{\partial x_{j}}\left\{\left(\bar{\eta}+\frac{\eta_{t}}{\sigma_{Z^{\prime \prime 2}}}\right) \frac{\partial \widetilde{Z^{\prime \prime 2}}}{\partial x_{j}}\right\}+2 \frac{\eta_{t}}{\sigma_{Z}}\left(\frac{\partial \tilde{Z}}{\partial x_{j}}\right)^{2} .
\end{aligned}
$$

The scalar dissipation rate $\chi$ is a very important quantity since it couples the flamelet solutions with the flow field. With the mixture fraction diffusion coefficient $D_{Z}$ chosen as thermal diffusivity, the scalar dissipation rate is defined as $\chi=2 D_{Z}(\nabla Z)^{2}$. The mean scalar dissipation rate is modeled by the correlation:

$$
\tilde{\chi}=C_{\chi} \frac{\tilde{\epsilon}}{\tilde{\kappa}} \widetilde{Z^{\prime \prime 2}} .
$$

The coefficient's default setting in CFX is given by $\sigma_{Z}=0.9, \sigma_{Z^{\prime \prime 2}}=0.9$, and $C_{\chi}=2$. As the CFD provides only the mean scalar dissipation rate $\tilde{\chi}$, this quantity has to be related to the mean scalar dissipation rate conditioned at stoichiometric conditions $\tilde{\chi}_{\text {st }}$. Assuming constant density and diffusivity, $\chi$ can be approximated according to [1] as

$$
\chi(Z)=\frac{a_{s}}{\pi} \underbrace{\exp \left\{-2\left[\operatorname{erfc}^{-1}(2 Z)\right]^{2}\right\}}_{f(Z)} .
$$

Here, erfc ${ }^{-1}$ denotes the inverse of the complementary error function. Furthermore it can be stated that

$$
\tilde{\chi}(Z)=\chi\left(Z_{\mathrm{st}}\right) \frac{f(Z)}{f\left(Z_{\mathrm{st}}\right)} .
$$


Applying Eq. (17), finally $\tilde{\chi}_{\text {st }}$ can be calculated from [1]:

$$
\tilde{\chi}_{\mathrm{st}}=\frac{C_{\chi}(\tilde{\epsilon} / \tilde{k}) \widetilde{Z^{\prime \prime 2}} f\left(Z_{\mathrm{st}}\right)}{\int_{0}^{1} f(Z) \tilde{P}(Z) d Z} .
$$

In CFX, however, the solver uses the local value of the scalar dissipation rate $\tilde{\chi}$ instead of its value at stoichiometric mixture fraction $\tilde{\chi}_{\text {st }}$ as an approximation for the flamelet library lookup [35]. As this is the standard procedure in CFX, it has also been applied for the CFD-simulation results presented within this work.

\section{COUNTERFLOW DIFFUSION FLAMES AT SUPERCRITICAL PRESSURES}

Based on the numerical framework established above, the influence of modeling real fluids, differential and thermal diffusion as well as the effect of pressure on the detailed structure of $\mathrm{H}_{2} / \mathrm{O}_{2}$ counterflow diffusion flames is analyzed in this chapter for trans- and supercritical thermodynamic states. Special emphasis is placed on calculations at the conditions of the RCM-3 test case, defined at the 2nd International Workshop on Rocket Combustion Modeling [37, 38]. This test case is used for the validation of the real gas CFD simulations presented in section 4 . Here, hydrogen is injected in a supercritical state at $T_{\mathrm{H}_{2}}=287 \mathrm{~K}$ at a combustion chamber pressure of $p=60$ bar. The state of oxygen, however, is transcritical due to an injection temperature of $T_{\mathrm{O}_{2}}=85 \mathrm{~K}$.

The presentation of the results is subdivided into three parts. First, the validation of the real gas treatment regarding the thermodynamic and transport properties of pure oxygen is reviewed. Second, the detailed structure of the counterflow diffusion flame is investigated for typical rocket combustion conditions. Especially, differential diffusion effects and their impact on the flame structure are examined. The pressure influence as well as the influence of thermal diffusion is finally assessed for the real fluid approach in the last section.

\subsection{Validation of Thermodynamic and Transport Properties}

An accurate modeling of the thermodynamic and transport properties is crucial for a reliable prediction of real gas flows. It provides the basis for analyzing the detailed structure of the counterflow diffusion flame. The real gas formulations outlined above for the thermodynamic and transport properties have already been validated against NIST data [39] as published in the previous work performed by Poschner and Pfitzner [6,7]. The main results for pure oxygen are 

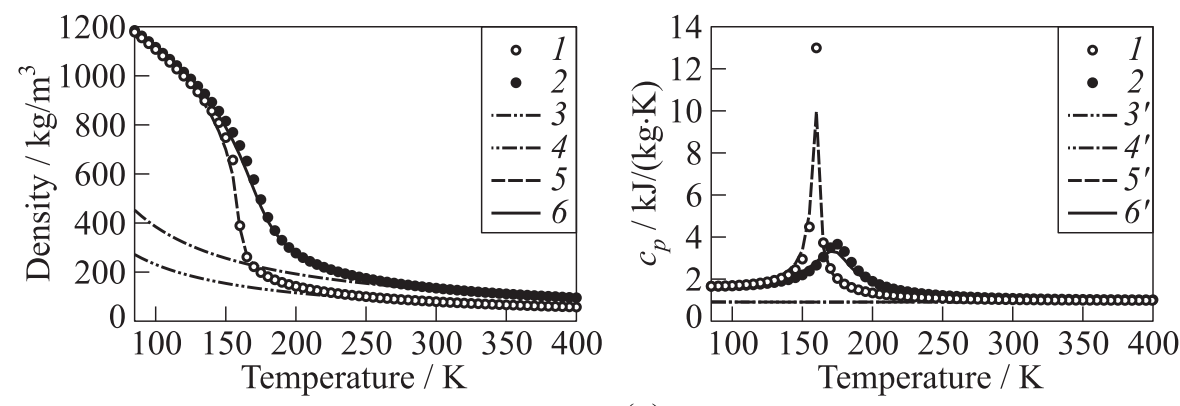

(a)
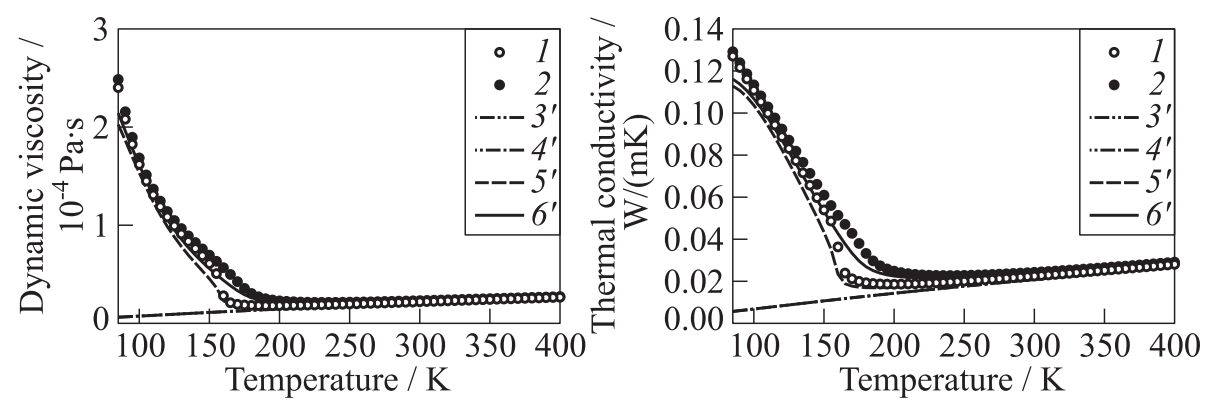

(b)

Figure 2 Validation of predicted thermodynamic $(a)$ and transport $(b)$ properties of pure oxygen against NIST data [39] for supercritical pressures: 1 - NIST, 60 bar; 2 - NIST, 100 bar; 3 - ideal gas EOS, 60 bar; $3^{\prime}$ — ideal fluid, 60 bar; 4 - ideal gas EOS, 100 bar; $4^{\prime}$ - ideal fluid, 100 bar; 5 - PR EOS, 60 bar; $5^{\prime}$ - real fluid, 60 bar; 6 - PR EOS, 100 bar; and $6^{\prime}$ - real fluid, 100 bar

reviewed again in Fig. 2 for the supercritical pressures 60 and 100 bar. However, the injection of hydrogen into the rocket combustion chamber typically occurs at pressures and temperatures which are above their critical values and thus at the supercritical state. Comparing the ideal and the real gas thermophysical properties of hydrogen at these conditions, only small differences were found [6]. The validation of the hydrogen properties is therefore not included here.

For the calculation of the oxygen density, the PR EOS with the volume correction fits the NIST data very well. Particularly, the application of the volume correction prevents the over-prediction of the density at subcritical temperatures $T<T_{\text {crit, } \mathrm{O}_{2}}=154.6 \mathrm{~K}$ which has been observed while using the simple PR equation [6]. The ideal gas EOS, however, is not able to predict the transition from transcritical to supercritial conditions correctly: at the injection temperature of oxygen $T_{\mathrm{O}_{2}}=85 \mathrm{~K}$ the density is underestimated by a factor of about 4 and 2.5 for the 60 - and the 100-bar cases, respectively. 
Likewise, the PR EOS predicts the heat capacity at constant pressure $c_{p}$ sufficiently well. By default, $c_{p}$ is evaluated from the NASA polynomials [28] for the ideal gas case. Since these polynomials only depend on the temperature, the pressure influence cannot be captured here.

The validation of the transport properties is shown in Fig. 2b. Here, Chung's formulation for dense fluids is used for the real gas approach (Eqs. (11) and (12)) while his correlation for dilute gases is applied for the ideal gas assumption (Eqs. (10) and (13)). Of course, the pressure influence cannot be reproduced by the ideal gas EOS, neither for the dynamic viscosity nor for the thermal conductivity. For the real gas model, the effects of pressure as well as the transition from sub- to supercritical temperatures are predicted in close agreement to the NIST data [39].

\subsection{Structures of Counterflow Diffusion Flames}

In order to analyze the influence of real fluid modeling on the local structure of hydrogen/oxygen counterflow diffusion flames, the reaction mechanism developed by Ó Conaire et al. [40] is employed. It contains 8 reacting species $\mathrm{H}, \mathrm{H}_{2}$, $\mathrm{O}, \mathrm{O}_{2}, \mathrm{OH}, \mathrm{H}_{2} \mathrm{O}, \mathrm{HO}_{2}$, and $\mathrm{H}_{2} \mathrm{O}_{2}$ with 19 reversible reactions. The validation against experimental data has been performed successfully by these authors for temperatures ranging from 298 to $2700 \mathrm{~K}$ and pressures from 0.05 to 87 atm [40]. The influence of applying different detailed reaction mechanisms was tested by Ribert et al. [12]. As the results were found to be almost identical for all applied mechanisms, only the Ó Conaire mechanism is considered here.

Within the present work, the 4 different approaches listed in Table 3 were used for a detailed analysis of the counterflow diffusion flames. The first two of them use the ideal gas EOS along with the ideal treatment of thermophysical properties

Table 3 Simulation settings used to analyze the counterflow diffusion flames

\begin{tabular}{lcccc}
\hline Approach & Ideal 1 & Ideal 2 & Real 1 & Real 2 \\
\hline \multirow{2}{*}{ EOS } & Ideal gas & Ideal gas & $\begin{array}{c}\text { Volume- } \\
\text { corrected } \\
\text { PR EOS }\end{array}$ & $\begin{array}{c}\text { Volume- } \\
\text { corrected } \\
\text { PR EOS }\end{array}$ \\
\hline$c_{p}, h_{i}$ & $\begin{array}{c}\text { NASA } \\
\text { polynomials }\end{array}$ & $\begin{array}{c}\text { NASA } \\
\text { polynomials }\end{array}$ & $\begin{array}{c}\text { Real fluids: } \\
\text { Eqs. }(7),(8)\end{array}$ & $\begin{array}{c}\text { Real fluids: } \\
\text { Eqs. (7), (8) }\end{array}$ \\
\hline$\lambda, \eta$ & Dilute gases: & $\begin{array}{c}\text { Dilute gases: } \\
\text { Eqs. }(10),(13)\end{array}$ & $\begin{array}{c}\text { Dense fluids: } \\
\text { Eqs. }(10),(13)\end{array}$ & $\begin{array}{c}\text { Eqs. }(11),(12) \\
\text { Dense fluids: } \\
\text { Eqs. (11), (12) }\end{array}$ \\
\hline Le & 1 & Le $_{i}$ & 1 & Le $_{i}$ \\
\hline$D_{i, j}$ & $\lambda /\left(\rho c_{p}\right)$ & Fuller & $\lambda /\left(\rho c_{p}\right)$ & Fuller + pressure \\
& & Eq. (14) & & correction: Eqs. (14), (15) \\
\hline$D_{i}^{T}$ & - & - & - & Eq. (16) \\
\hline
\end{tabular}



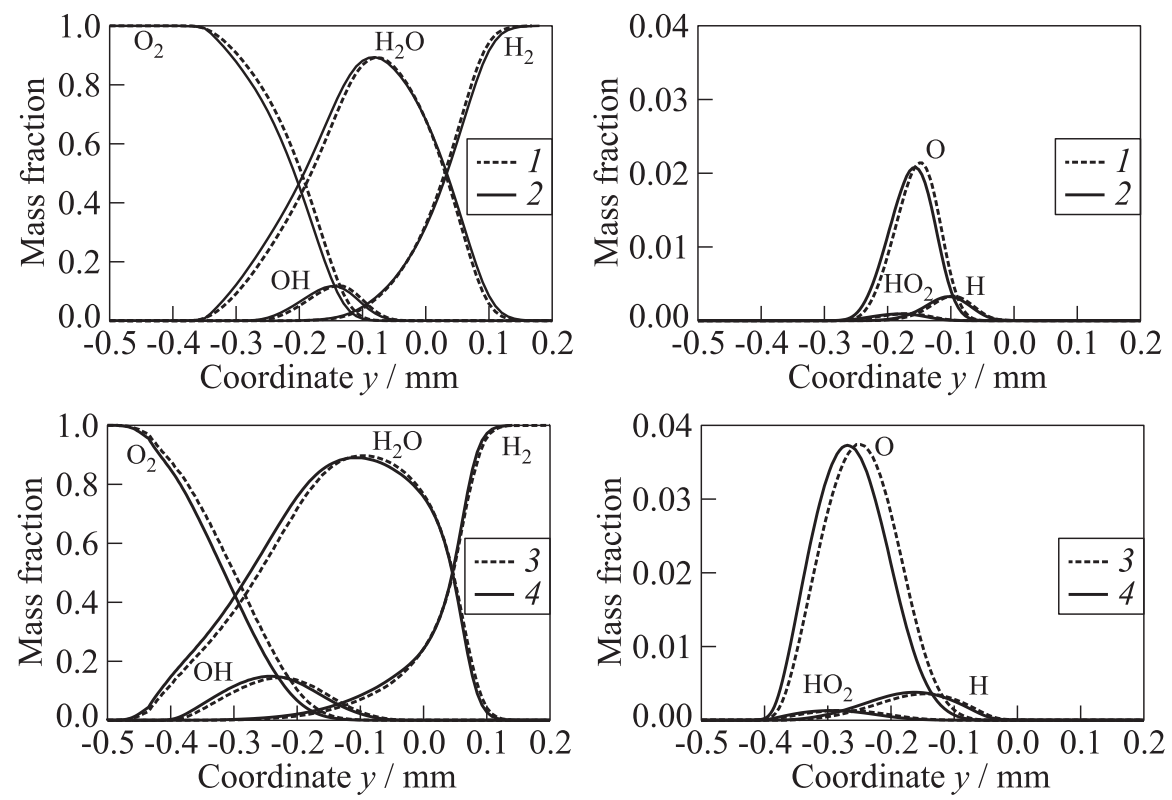

(a)

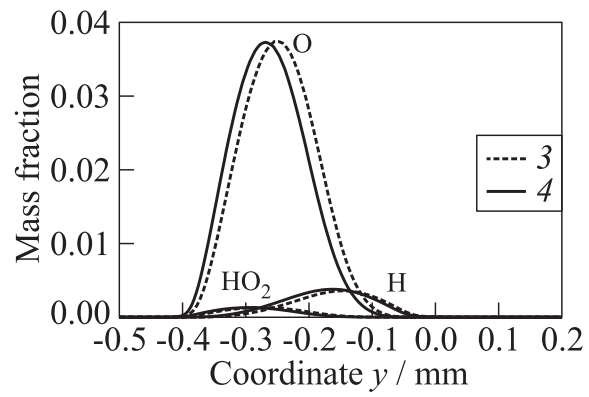

(b)

Figure 3 Distribution of major $(a)$ and minor species mass fraction $(b)$ for the settings listed in Table $3\left(p=60\right.$ bar and $\left.a_{s}=1000 \mathrm{~s}^{-1}\right): 1$ - Ideal $1 ; 2$ - Real 1; 3 - Ideal 2; and 4-Real 2. Upper row refers to Le $=1$ and lower - to consideration of differential diffusion effects

(Ideal 1 and 2), whereas for the remaining two, the volume-corrected PR EOS has been applied together with an appropriate modeling of thermodynamic and transport properties (Real 1 and 2). In both cases, one simulation is carried out with unity Lewis number while the other includes differential diffusion effects. The Soret-effect is considered only for the real fluid approach (Real 2) by applying Eq. (16).

The results are presented in Figs. 3 and 4 as functions of the axial distance $y$. In the upper row, the profiles resulting from the approaches Ideal 1 and Real 1 are given for the Lewis number equal to unity. In the lower row, differential diffusion effects are considered (approaches Ideal 2 and Real 2). The strain rate is set to $1000 \mathrm{~s}^{-1}$. As stated above, the pressure as well as the inlet temperature of the fuel and the oxidizer are set according to the Mascotte RCM-3 test conditions with $p=60$ bar, $T_{\mathrm{H}_{2}}=287 \mathrm{~K}$, and $T_{\mathrm{O}_{2}}=85 \mathrm{~K}$. All diagrams use the stagnation point $\left(v_{y=0}=0\right)$ as the common reference position.

Comparing the ideal and the real treatment for the unity Lewis number approach first (see Figs. 3 and 4, upper rows), only small differences are found for the species mass fractions and the temperature distribution. As expected 

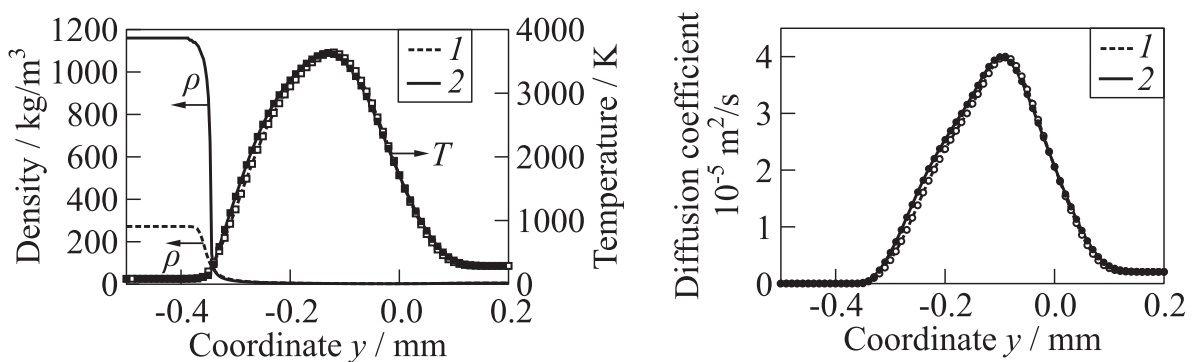

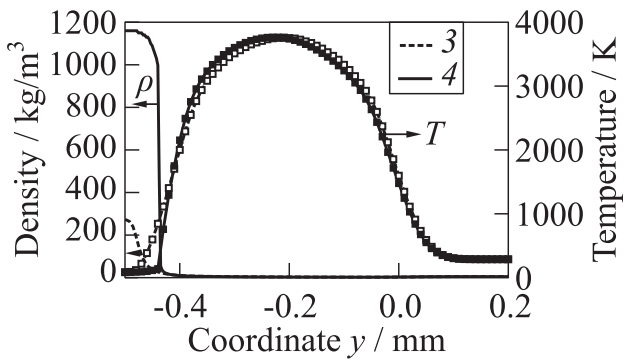

(a)

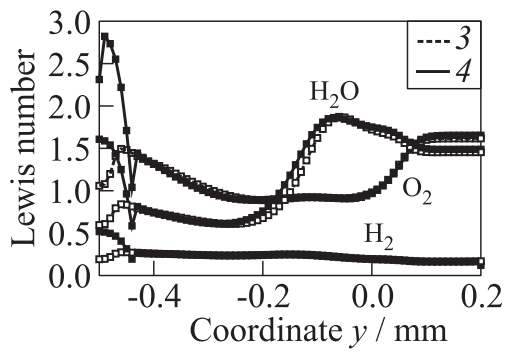

(b)

Figure 4 Density and temperature distribution $(a)$ and diffusion coefficient and Lewis number $(b)$ at $p=60$ bar and $a_{s}=1000 \mathrm{~s}^{-1}: 1$ - Ideal $1 ; 2$ - Real $1 ; 3$ Ideal 2; and 4 - Real 2. Upper row refers to Le $=1$ and lower - to consideration of differential diffusion effects

from the analysis of the oxygen thermodynamic properties above (see Fig. 2a), the oxygen density is highly underestimated when applying an ideal gas EOS. The diffusion coefficients calculated with Eq. (6) and Le $=1$ are identical for all species. They are shown for both approaches in Fig. $4 b$. Due to the different modeling of thermodynamic and transport properties, the profile of the real gas diffusion coefficient (Real 1) is shifted slightly towards the oxygen side. Similarly, this causes the species mass fraction and temperature distribution also to move towards the same side. However, the overall influence of the real gas treatment assuming the Lewis number of unity seems to be limited.

In the lower rows of Figs. 3 and 4, the same quantities are compared including differential diffusion effects. Here, the shift of species mass fraction and temperature distributions towards the oxygen inlet is much more evident than for the unity Lewis number cases. Larger deviations can also be detected for the density gradient and the temperature profile in the cold oxygen rich region. When the oxygen heats up, almost identical profiles are found for the density and the temperature distribution within the flame zone.

The major species Lewis numbers are presented in Fig. $4 b$. Here, significant differences between the ideal and the real fluid approach can be found particularly 
close to the oxygen inlet. As a reason, the disability of the ideal gas approach (Ideal 2) to capture the steep gradients in the species' thermophysical properties during the transition from trans- to supercritical state can be identified. Also, the Lewis number of hydrogen is much smaller than unity, indicating that for this species the mass diffusion is significantly enhanced over the thermal diffusivity. It varies only slightly around the value of 0.25 while the Lewis numbers of $\mathrm{O}_{2}$ and $\mathrm{H}_{2} \mathrm{O}$ change rapidly within the high temperature flame zone.

Finally, the local flame structure resulting from the unity and the variable Lewis number method are compared to each other. Two major differences can be observed from the results. First, the flame thickness is increased significantly when the differential diffusion effects are included. Defining the flame thickness according to Ribert [12] as the full width at half maximum of the temperature profile, values of 0.39 and $0.28 \mathrm{~mm}$ are calculated for the approaches Real 1 and Real 2, respectively. This corresponds to the increase in the flame thickness of about $40 \%$ based on the unity Lewis number approach. Also, the maximum flame temperature is about $135 \mathrm{~K}$ higher for the Real 2 calculation than that for Real 1. Second, the profiles of all species mass fractions and especially those of the minor species ones are shifted considerably towards the oxygen inlet if differential diffusion is considered. This can be explained by the high diffusivity of hydrogen which causes more $\mathrm{H}_{2}$ to diffuse towards the oxygen side and finally results in a shift of the flame zone and an increased flame thickness. The increase in the minor species maximum mass fraction results from the overall higher temperature predicted by applying differential diffusion processes.

\subsection{Influence of Thermal Diffusion and Pressure}

As the mass diffusion caused by a temperature gradient, also referred to as thermal diffusion or Soret-effect, was found to be an important effect for propellants like hydrogen [5], it is examined in Fig. 5. Besides the major species mass fractions, the density as well as the temperature profile are presented vs. the axial distance. The Real 2 approach is used for this purpose with and without modeling thermal diffusion effects according to Eq. (16).

Generally, thermal diffusion causes light molecules to diffuse towards the hot temperature region whereas heavy molecules are driven into the opposite direction. Ribert et al. [12] already observed that the influence of thermal diffusion is slightly enhanced on the oxygen rich side since hydrogen reacts rapidly with other species. This observation is also reflected in Fig. 5 where, e.g., a moderate change of the $\mathrm{O}_{2}$ mass fraction profile towards the cold oxygen inlet can be detected for the calculation including thermal diffusion. The maximum flame temperature is about $29 \mathrm{~K}$ higher for this case whereas almost no influence can be found for the flame thickness. 


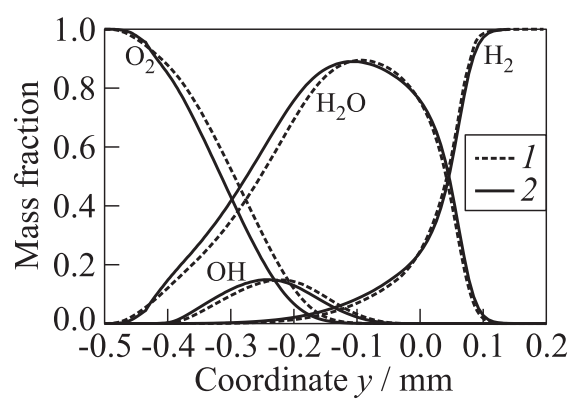

(a)

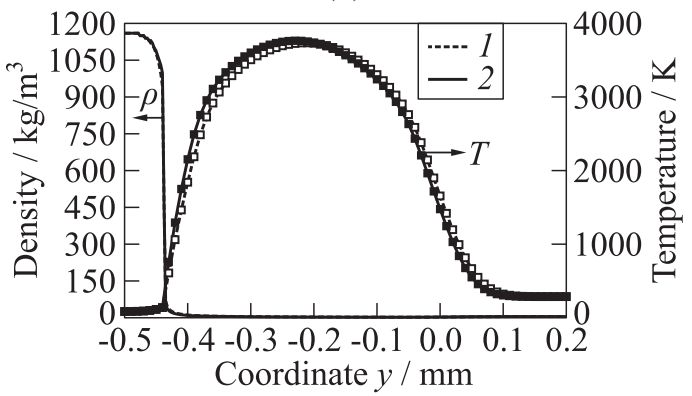

(b)

Figure 5 Influence of the thermal diffusion process $(1-$ without and 2 - with thermal diffusion) on the major species mass fractions $(a)$ as well as on the density and the temperature profile $(b)$ at $p=60$ bar and $a_{s}=1000 \mathrm{~s}^{-1}$

The local structure of the $\mathrm{H}_{2} / \mathrm{O}_{2}$ counterflow diffusion flame has also been analyzed for the supercritical pressures of 60,100 , and 120 bar. The results are presented in Fig. 6 . Again, the inlet temperatures of the propellants are set according to the Mascotte RCM-3 test case conditions with $T_{\mathrm{H}_{2}}=287 \mathrm{~K}$ and $T_{\mathrm{O}_{2}}$ $=85 \mathrm{~K}$. The strain rate is fixed at $a_{s}=1000 \mathrm{~s}^{-1}$. As numerical setting, the real fluid approach Real 2 listed in Table 3 is employed. With increasing pressure at constant strain rate, the flame is getting thinner and the maximum temperature is increased. Based on the 60 bar

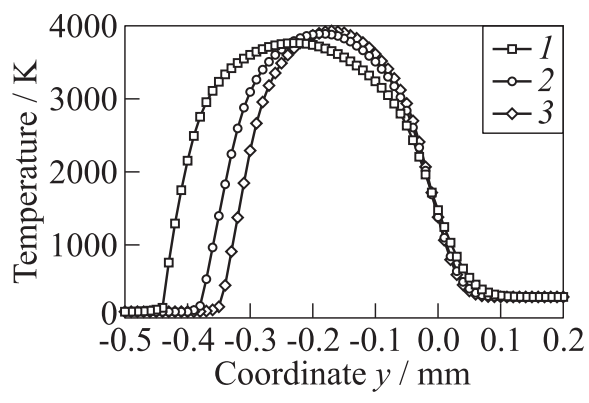

Figure 6 Temperature profiles for the $\mathrm{H}_{2} / \mathrm{O}_{2}$ counterflow diffusion flame at different supercritical pressures with Real 2 modeling at $a_{s}=1000 \mathrm{~s}^{-1}: 1-60 \mathrm{bar} ; 2-100$; and $3-120$ bar 
profile for example, the maximum flame temperature is about 128 and $160 \mathrm{~K}$ higher for the 100 and the 120 bar case, respectively. These results are found to be consistent with observations from other researchers $[2,12]$.

\section{APPLICATION}

Consistent real gas CFD simulations are performed within this work applying the real gas laminar flamelet combustion model established above. As application, the A-60 case tested at the Mascotte test rig V03 operated at ONERA is used [37, 38] which also allows for the validation of the obtained results. The experimental setup and the corresponding CFD model are summarized briefly whereas the results are discussed in detail with respect to the flamelet solutions, the flame shapes and the comparison with experimental findings.

\subsection{Experimental Test Case}

The experimental setup of the A-60 test case corresponds to the RCM-3 case defined at the 2nd International Workshop on Rocket Combustion Modeling. The combustion chamber is a square duct with an inner edge length of $50 \mathrm{~mm}$ and a total chamber length of $458 \mathrm{~mm}$. The throat diameter of the variable shape nozzle is $9 \mathrm{~mm}$ and its convergent length is $20 \mathrm{~mm}$. Four silica windows whose inner surface is cooled by a gaseous helium film allow for optical access to the chamber. The combustor is equipped with one single coaxial injection element as illustrated in Fig. 7. The diameter of the central oxygen injector is $3.6 \mathrm{~mm}$ at the inlet and $5 \mathrm{~mm}$ at the outlet corresponding to a taper angle of $8^{\circ}$. The hydrogen is injected coaxially through an annulus with dimensions of $5.6 \mathrm{~mm}$ inner and $10 \mathrm{~mm}$ outer diameter.

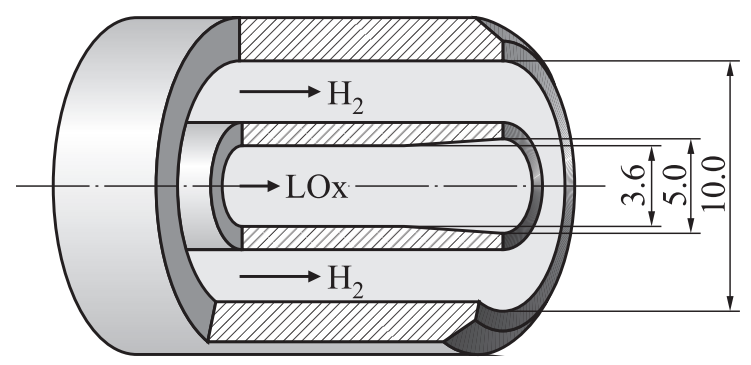

Figure 7 Detail A — Mascotte single coaxial injector element adapted from [38]. Dimensions are in millimeters 
Table 4 Operating conditions of the RCM-3 case [38]

\begin{tabular}{cccccc}
\hline Species & $\begin{array}{c}\text { Pressure, } \\
\mathrm{MPa}\end{array}$ & $\begin{array}{c}\text { Mass flow } \\
\text { rate, } \mathrm{g} / \mathrm{s}\end{array}$ & $\begin{array}{c}\text { Temperature, } \\
\mathrm{K}\end{array}$ & $\begin{array}{c}\text { Density, } \\
\mathrm{kg} / \mathrm{m}^{3}\end{array}$ & $\begin{array}{c}\text { Velocity, } \\
\mathrm{m} / \mathrm{s}\end{array}$ \\
\hline $\mathrm{H}_{2}$ & 6 & 70 & 287 & 5.51 & 236 \\
$\mathrm{O}_{2}$ & 6 & 100 & 85 & 1177.8 & 4.35 \\
\hline
\end{tabular}

The operating conditions used for the RCM-3 case are summarized in Table 4 . With $6 \mathrm{MPa}$ the chamber pressure is above the critical pressure of oxygen $\left(p_{\mathrm{O}_{2}}\right.$ $>p_{\text {crit, } \mathrm{O}_{2}}=5.04 \mathrm{MPa}$ ) whereas the injection temperature of $85 \mathrm{~K}$ is below its critical value $\left(T_{\mathrm{O}_{2}}<T_{\text {crit, } \mathrm{O}_{2}}=154.6 \mathrm{~K}\right)$. Hydrogen, however, is injected in a supercritical state.

\subsection{Simplified CFD-Model}

For the numerical investigations, the quasi-two-dimensional model given in Fig. 8 is used. It has been established by Poschner and Pfitzner [6, 7] in their previous works and models a rotationally symmetric combustion chamber with a radius of $28.81 \mathrm{~mm}$ in order to reproduce the internal chamber volume. A total length of $50 \mathrm{~mm}$ has been applied for the injector to receive a fully turbulent inlet flow profile. At the outlet, backflow is avoided by fitting the nozzle with a minimum diameter of $15 \mathrm{~mm}$. For the quasi-two-dimensional model, a sector of $2^{\circ}$ circumferential extent is considered and discretized with $200 \times 1700$ hexahedral elements (radial $\times$ axial direction), providing a grid resolved solution. The film cooling of the windows is neglected here.

As inlet conditions, the mass flow rates of fuel and oxidizer are prescribed according to Table 4 . As defined for the RCM-3 test case, the average static pressure is set to the value of $6 \mathrm{MPa}$ at the outlet. All walls are assumed to be no-slip adiabatic walls.

For the RANS-based real gas CFD simulations of the Mascotte test case, the commercial CFD code ANSYS CFX [35] is used along with proper real

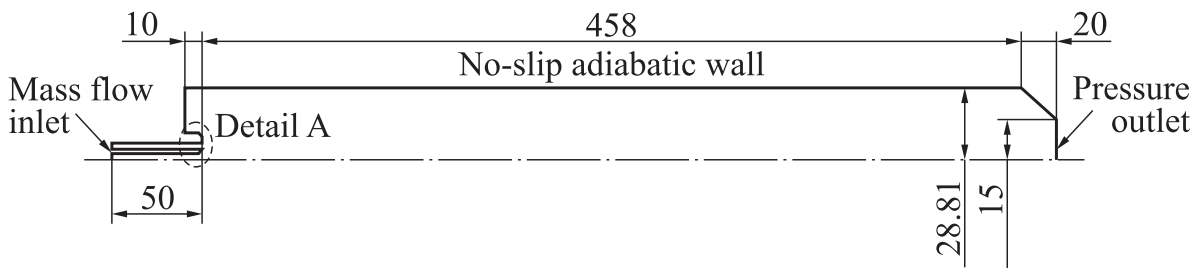

Figure 8 Schematic view of the computational domain used for the CFD simulations. Dimensions are in millimeters 
gas relations implemented and validated in $[6,7]$. As for the analysis of the counterflow diffusion flames, the real gas modeling described in section 2.1 is also applied within the CFD simulations. Consistently, the density is determined from the volume-corrected PR EOS and all other thermodynamic properties such as enthalpy, entropy and specific heat capacity are calculated as the sum of an ideal gas reference value at low pressure and a departure function accounting for real gas effects. Since detailed investigations of the real gas mixing procedure [7] underlined that its influence on the flame structure is negligibly small, the CFX standard mixing procedures have been applied here for all thermodynamic and transport properties in order to save computational resources. Regarding the transport properties, laminar effects were found to be unimportant in turbulent flames [6]. Thus, the rigid non interacting sphere model available in CFX is used to determine the dynamic viscosity while the thermodynamic conductivity is calculated based on the modified Eucken model.

The system of Favre-averaged equations is closed by applying the standard $k-\epsilon$ turbulence model. Two additional equations, one for the mixture fraction $\widetilde{Z}$ and another for its variance $\widetilde{Z^{\prime \prime 2}}$, have to be solved when using the steady flamelet model available in CFX. The underlying flamelet libraries are obtained with the flamelet code COSILAB and the real gas approach described above. In order to model nonpremixed turbulent combustion, flamelets are typically generated at unity Lewis number. Here, the following 4 different types of flamelets are considered:

(1) ideal gas flamelet library at unity Lewis number $\left(\mathrm{Le}_{i}=1\right)$;

(2) real gas flamelet library at unity Lewis number $\left(\mathrm{Le}_{i}=1\right)$;

(3) real gas flamelet library including differential diffusion effects $\left(\mathrm{Le}_{i}\right)$; and

(4) mixed real gas flamelet library including differential diffusion effects in the flame zone while assuming a unity Lewis number elsewhere.

The libraries are obtained using a nonuniform distribution of 100 points in $\widetilde{Z}$ and 10 equally spaced points in $\widetilde{Z^{\prime \prime 2}}$ direction. The strainrate was varied from near equilibrium up to flame extinction, including also one unburnt flamelet solution. For the mixed flamelet library, two flamelet solutions close to equilibrium $\left(a_{s}=\right.$ 50 and $\left.100 \mathrm{~s}^{-1}\right)$ as well as the unburnt one are considered at unity Lewis number. In order to account for the high diffusivity of hydrogen in the flame zone, all other flamelets at higher strainrates $\left(a_{s} \geq 500 \mathrm{~s}^{-1}\right)$ include differential diffusion effects.

The governing equations are solved applying the CFX high resolution spatial discretization scheme. This adaptive method blends between the first-order upwind discretization in regions with steep gradients and the second-order technique based on the local solution field to maintain robustness of the solution procedure [35]. Additionally, a sufficiently high, spatially grid converged resolution allows for a numerically adequate treatment of steep gradients. Only for 
the mixture fraction variable an upwind technique is used. However, a massive underrelaxation was required to obtain a converged solution.

\subsection{Results and Discussion}

\subsubsection{Flamelet library}

As a first step, the flamelet solutions stored in the generated flamelet libraries are analyzed for the major species mass fractions, the temperature and the density distribution in the mixture fraction space shown in Figs. 9 and 10.

Although not stored in the library, the mixture temperature and the density are also included here to emphasize their influence in the CFD simulations. The distribution of the mixture fraction resulting from the transport equation (5) solved in COSILAB is considered likewise, as it is used as the independent coordinate for the flamelet library. All results are presented for one strainrate

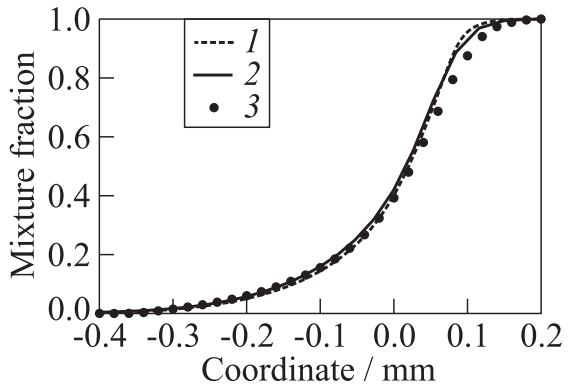

(a)

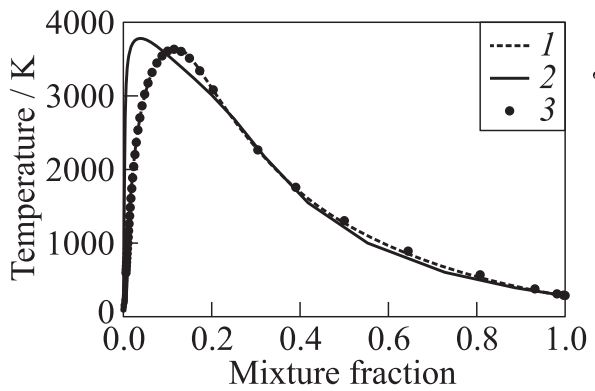

(c)

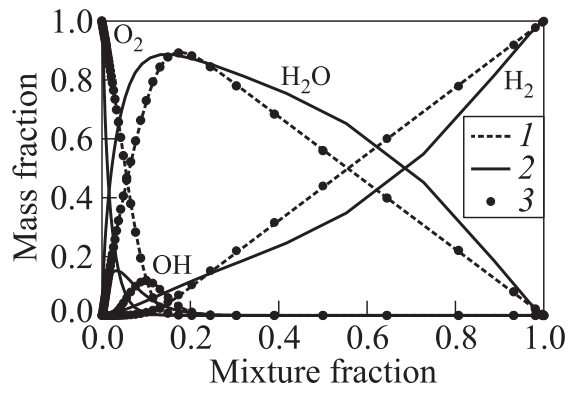

(b)

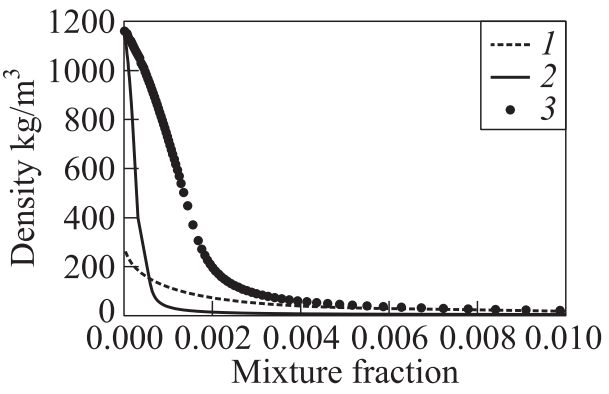

(d)

Figure 9 Flamelet solutions calculated by the ideal $\left(1-\mathrm{Le}_{i}=1\right)$ and the real gas approaches with (2) and without differential diffusion $\left(3-\mathrm{Le}_{i}=1\right)$ at $p=60$ bar, $a_{s}=1000 \mathrm{~s}^{-1}$ : (a) mixture fraction; (b) major species mass fraction; $(c)$ temperature; and $(d)$ density 


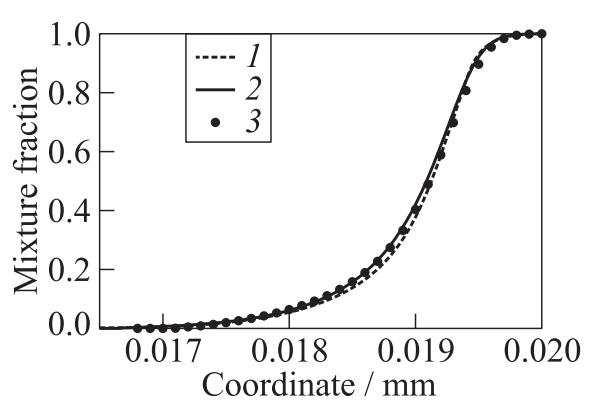

(a)

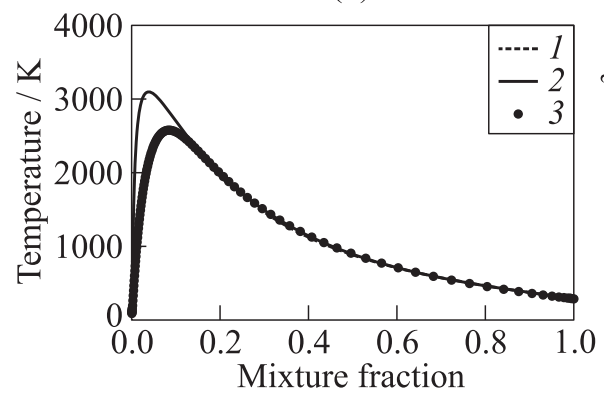

(c)

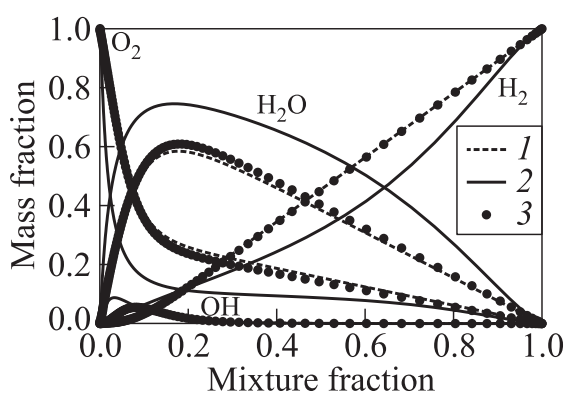

(b)

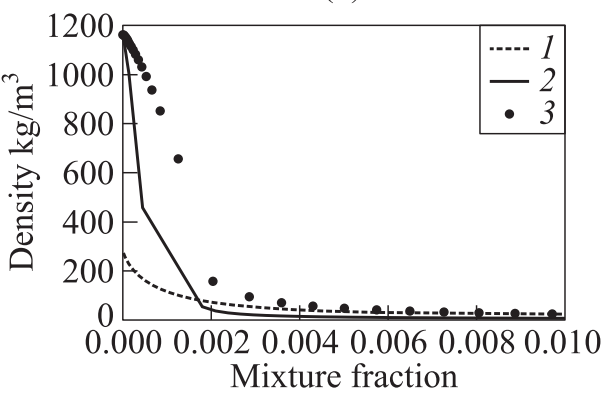

(d)

Figure 10 Flamelet solutions calculated by the ideal $\left(1-\mathrm{Le}_{i}=1\right)$ and the real gas approaches with $\left(2-\mathrm{Le}_{i}\right)$ and without $\left(3-\mathrm{Le}_{i}=1\right)$ differential diffusion at $p=60$ bar, $a_{s}=2.5 \cdot 10^{7} \mathrm{~s}^{-1}:(a)$ mixture fraction; $(b)$ major species mass fraction; (c) temperature; and $(d)$ density

close to the equilibrium $\left(a_{s}=1000 \mathrm{~s}^{-1}\right)$ and another one close to the extinction $\left(a_{s}=2.5 \cdot 10^{7} \mathrm{~s}^{-1}\right)$. Here, the strain rate $a_{s}$ is given since it is the precribed quantity for the flamelet equations solved in physical space. For the generation of the flamelet library $a_{s}$ has to be linked to the scalar dissipation rate at stoichiometric conditions, e. g., by applying Eq. (18).

In Fig. $9 a$, the stagnation point $\left(v_{y=0}=0\right)$ is taken as the common reference position for all three cases to plot the distribution of the mixture fraction in physical space. Here, only minor differences can be seen on the fuel-rich side $(0<y<0.2 \mathrm{~mm})$. Significant changes, however, appear for the species mass fractions, the density and the temperature of the mixture. As already discussed for the flame structures in physical space, the resulting profiles are similar for the ideal and the real gas approach assuming a unity Lewis number except for the density which is highly underestimated by the ideal gas EOS on the oxygen side. If differential diffusion processes are considered $\left(\mathrm{Le}_{i} \neq 1\right)$, the flame structure changes considerably since different diffusion coefficients are applied in the transport equations for the species mass fractions and the mixture fraction. 
For the latter one, $\mathrm{Le}_{Z}=1$ is still valid if $D_{Z}$ is estimated from the mixture properties. Effects like a higher maximum temperature, the shift of the temperature profile towards the oxygen inlet as well as a steeper density gradient are much more enhanced if the mixture fraction variable is taken as the independent coordinate.

Similar results are also obtained for the flamelet solution near extinction presented in Fig. 10. Here, small differences are also present for the unity Lewis number approaches whereas the influence of differential diffusion becomes even more enhanced compared to the near-equilibrium case. The calculated maximum flame temperature is considerably lower and it will decrease until the flame extinction if the strainrate exceeds a critical limit. Especially for the cases with a steep density gradient, it was very difficult to achieve a steady flamelet solution applying a fine spatial resolution. Instead, a coarse grid had to be used for the real gas flamelet generation with differential diffusion. This is also the reason for the slope discontinuities in the real gas density distribution shown in Fig. $10 d$. However, it is worth noting that this does not effect the solution's accuracy as the density is not a dependent variable here. A continuous improvement of both the solver and the self-adaptive gridding procedure in Cosilab is to be aimed at in the future. The findings presented here are generally in good agreement with recently presented results $[9,10]$.

\subsubsection{Comparison of flame shapes}

The simulation results obtained for the gaseous hydrogen cryogenic liquid oxygen flames are presented in Figs. 11 and 12 for the temperature and the $\mathrm{OH}$ radical mass fraction for different approaches of flow and combustion modeling. As the results are axially symmetric with respect to the combustion chamber center line, usually only one half of the flow field is illustrated here.

If the ideal gas EOS is applied for both the flow field and the combustion model (see Figs. $11 a$ and $12 a$ ), the flame propagates downstream for more than a half of the combustion chamber length. This is mainly caused by the highly overpredicted momentum flux of the oxygen jet at the inlet at given mass flow due to the underestimation of the oxygen density.

A considerably different flame shape can be detected for the fully consistent real gas approach when real gas thermodynamic relations are applied to the CFD and the combustion modeling (see Figs. $11 b$ and $12 b$ ). Here, the flame becomes much shorter due to the correct prediction of the inlet momentum flux. A strong radial expansion of the reaction zone can be detected at a position of around $75 \mathrm{~mm}$ downstream of the injector. As long as the flamelet library is based on a unity Lewis number the temperature as well as the $\mathrm{OH}$ radical exhibits an almost identical distribution regardless of whether real or ideal gas relations have been applied for the flamelet combustion model. The analysis of the flamelet solutions 


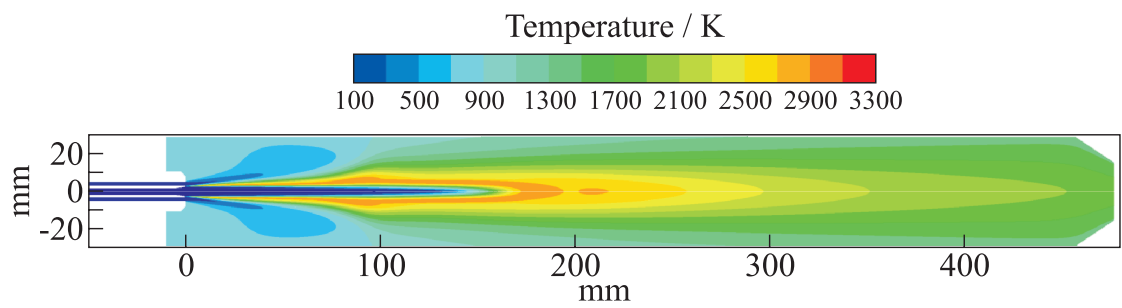

(a)

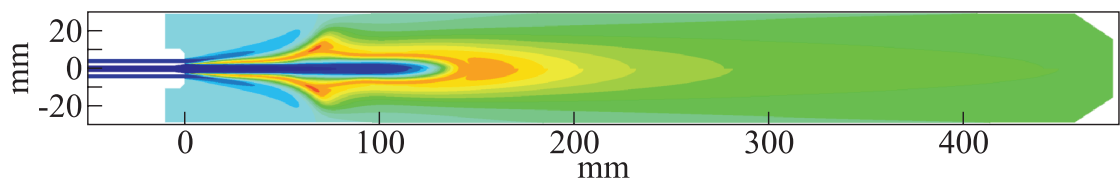

(b)

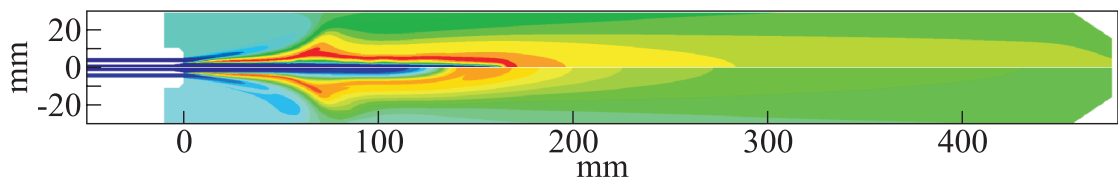

(c)

Figure 11 Comparison of the temperature distribution for different approaches of flow and combustion modeling: ( $a$ ) ideal gas - ideal flamelet $\left(\mathrm{Le}_{i}=1\right) ;(b)$ top - real gas-ideal flamelet $\left(\mathrm{Le}_{i}=1\right)$, and bottom - real gas-real flamelet $\left(\mathrm{Le}_{i}=1\right)$; and (c) top - real gas - real flamelet $\left(\mathrm{Le}_{i}\right)$, and bottom - real gas - real flamelet mixed.

in Figs. 9 and 10 has already underlined that the resulting species mass fraction distributions for the real and the ideal gas modeling at unity Lewis number are similar, especially for close to equilibrium flamelets. Although the calculated densities here differ significantly at the oxygen inlet, they can hardly influence the species mass fractions which are stored as a function of the mean mixture fraction, its variance and the scalar dissipation rate in the CFX flamelet library. Therefore, it could be expected that similar flamelet libraries also cause similar flame shapes.

If differential diffusion effects are considered in the generation of the flamelet library unrealistic results are obtained for the temperature distribution downstream of the main combustion zone as presented in the upper half of Fig. 11c. The following two reasons can be identified here. First, when applying differential diffusion relations within the flamelet calculation, the conservation of the chemical elements is violated locally as the species diffuse with different velocities throughout the computational domain. Element conservation can only be enforced by assuming the unity Lewis number for all species so that the thermal 


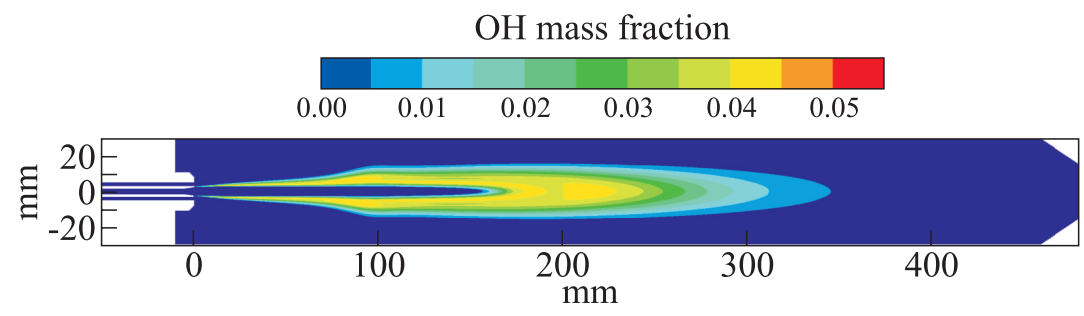

(a)

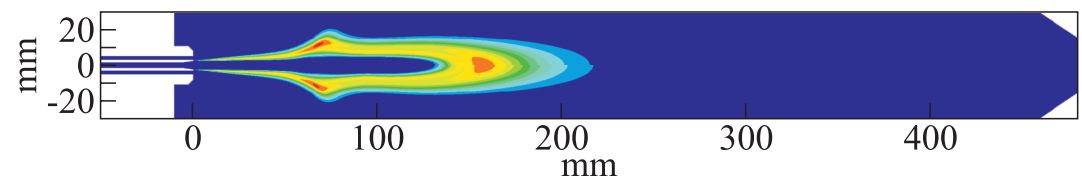

(b)

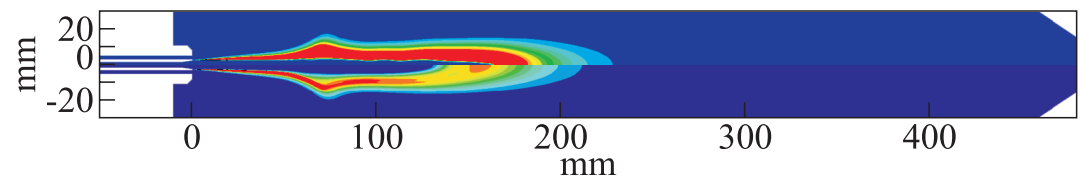

(c)

Figure 12 Comparison of the $\mathrm{OH}$ mass fraction distribution for different approaches of flow and combustion modeling: ( $a$ ) ideal gas-ideal flamelet $\left(\mathrm{Le}_{i}=1\right) ;(b)$ top real gas-ideal flamelet $\left(\mathrm{Le}_{i}=1\right)$, and bottom - real gas - real flamelet $\left(\mathrm{Le}_{i}=1\right)$; and (c) top - real gas - real flamelet $\left(\mathrm{Le}_{i}\right)$, and bottom - real gas - real flamelet mixed.

and mass diffusivities are equal. Furthermore, the CFX solver uses the local value of the scalar dissipation rate $\tilde{\chi}$ instead of its value at stoichiometric mixture fraction $\tilde{\chi_{s t}}$ as an approximation. This may also cause some inaccuracy for conditions farther away from the stoichiometric mixture fraction. It can be shown that these discrepancies finally lead to more O-atoms leaving the combustion chamber at the outlet than have been injected at the inlet in this simulation which is physically not possible.

The second reason arises from the fact that CFX solves for the enthalpy equation, while a temperature formulation is used in Cosilab. If differential diffusion effects are considered they also influence the resulting temperature distribution through the diffusion velocity $V_{i}$ in Eq. (4). In CFX, however, the enthalpy equation applied along with the flamelet combustion model is based on the unity Lewis number assumption. The temperature is then obtained using Newton's iteration procedure and comparing the enthalpy values resulting from the conservation equation with those calculated based on the species mass fractions stored in the flamelet library and the NASA polynomials. If now differ- 
ential diffusion is considered within the flamelet library, a significantly different mixture composition is looked up for one value of the mixture fraction compared to a Le $=1$ library (see Figs. 9 and 10). Depending on the temperature, also the enthalpy evaluated from the NASA polynomials will be different then whereas the conservation equation enthalpy remains similar for all simulated cases. This enthalpy difference is then compensated by the iteration procedure by in- or decreasing the resulting temperature of flow field, respectively.

As an example, the average mixture fraction at the combustion chamber outlet $(Z \approx 0.4)$ is considered. For scalar dissipations rates close to zero and only very small mixture fraction variances, a temperature of approximately $1700 \mathrm{~K}$ would be expected from the flamelet solutions shown in Fig. 9 for both approaches with and without differential diffusion. This is true for all cases where a Le $=1$ library has been applied. Including differential diffusion processes only in the flamelet library but not in the flow modeling, however, yields an average outlet temperature of more than $2000 \mathrm{~K}$ in the CFD simulation. Further investigations and an improvement of the coupling procedure of the laminar flamelet with the turbulent flow field in CFX are planned. Despite the local violation of the element conservation within the flamelet, the $\mathrm{OH}$ radical mass fraction remains unaffected as its values are looked-up in the flamelet library. The significantly elevated level can be explained by the increase of the radical concentration that was already observed for the flamelet solution (see Figs. $9 b$ and $10 b$ ). Furthermore, the results presented in Fig. 12 are scaled to a value of 0.055 while the maximum value for this simulation is about twice as high.

In turbulent combustion modeling, it is generally recognized that the assumption of a unity Lewis number yields good results whereas it is difficult to predict experimental findings in highly turbulent flames by combustion models considering differential diffusion effects $[9,11]$. Oefelein [23] underlined that preferential diffusion effects are important in the flame zone close to the injector. Thus, in order to still include the high diffusivity of hydrogen, a flamelet library was generated so that differential diffusion effects are considered in the flame zone while the unity Lewis number approach is applied elsewhere. As expected, the flame shape and length are similar to the real gas simulations with a Le $=1$ flamelet library in terms of temperature distribution. Since the maximum value of the $\mathrm{OH}$ concentration is higher and shifted towards smaller values of the mixture fraction variable (see Fig. 9b) compared to a unity Lewis number approach, an elevated radical level can also be detected in the flame front.

Different flame shapes and lengths result in differences in the region of the heat release and therefore also in the pressure built up in the combustion chamber. As the direct evaluation of the heat release rate is currently not possible for the flamelet combustion model in CFX, the static wall pressure development given in Fig. 13 is analyzed here.

In all cases, the maximum wall pressure is located at the axial position of the maximum flame spreading in radial direction. As expected from Fig. 11, 


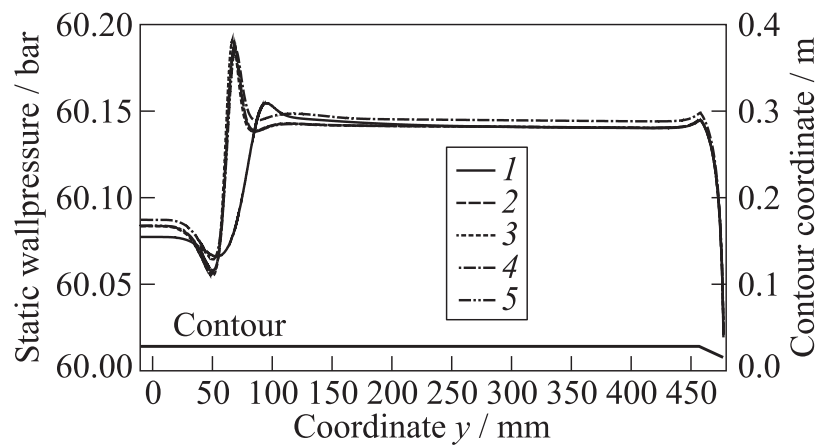

Figure 13 Static pressure distribution along the combustion chamber wall for different approaches of flow and combustion modeling: 1 - ideal gas-ideal flamelet $\left(\mathrm{Le}_{i}=1\right) ; 2$ - real gas -ideal flamelet $\left(\mathrm{Le}_{i}=1\right) ; 3$ - real gas-real flamelet $\left(\mathrm{Le}_{i}=1\right) ;$ 4 - real gas - real flamelet $\left(\mathrm{Le}_{i}\right)$; and 5 - real gas - real flamelet mixed

this position is located further downstream for the ideal gas flow modeling and is similar for all other cases. The pressure dip upstream of the maximum value results from the acceleration of the combustion gases within the recirculation zone. The overall pressure level is highest for the real gas flow including differential diffusion effects in the whole combustor. This is also consistent with the unphysically high temperatures obtained for this case. With an acceleration of the exhaust gases the static wall pressure decreases towards the end of the combustion chamber where a constant static pressure of 60 bar had been prescribed as outlet condition. This setting has already been recommended for the RCM-3 test case. It represents a common approach in combustion modeling as it allows for a detailed investigation of the flame due to a correct adjustment of the combustion chamber pressure.

Thus, the accurate prediction of the momentum flux at the inlet by applying proper real gas relations to the CFD modeling is of crucial importance in simulating gaseous hydrogen cryogenic liquid oxygen flames. Minor effects caused by real gas mixing rules as well as the modeling of the transport properties could be observed for the one dimensional counterflow diffusion flame but their influence onto the CFD simulation results remains limited.

\subsubsection{Validation}

Finally, the distribution of the $\mathrm{OH}$ radical mass fraction predicted by the CFD simulation is compared to experimental results available for the A-60 test case. For this reason, the fully consistent real gas approach is considered in Fig. 14 for two types of flamelets, one including differential diffusion in the flame zone by applying the mixed flamelet library $(a)$ and the other one at unity Lewis 


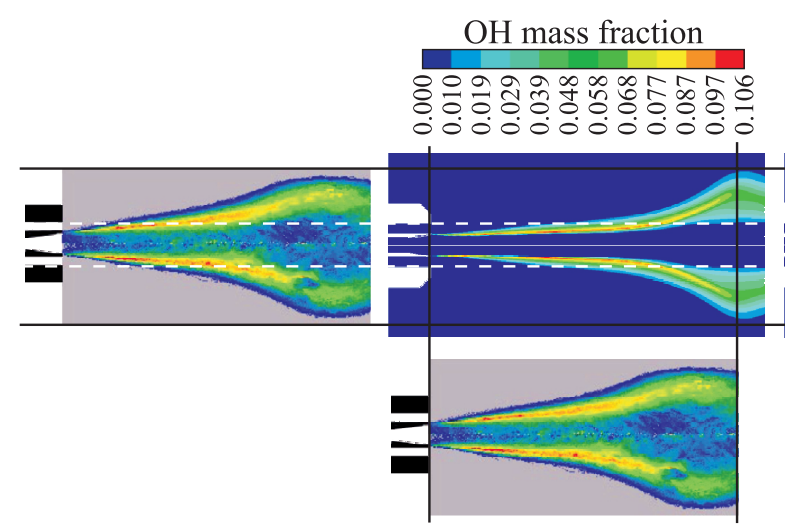

(a)

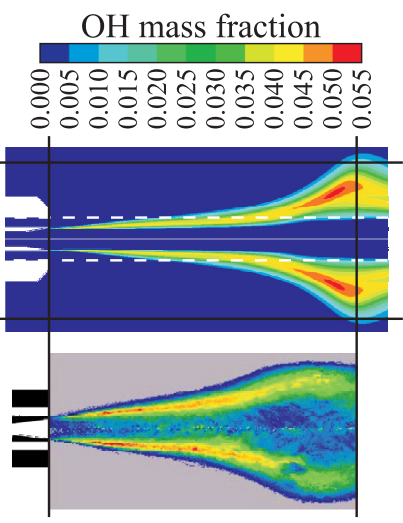

(b)

Figure $14 \mathrm{OH}^{*}$ Abel transformed emission image [37] compared to the $\mathrm{OH}$ concentration from CFD simulations applying the mixed real gas flamelet library including differential diffusion in the flame zone $(a)$ and the $\operatorname{Le}_{i}=1$ library $(b)$.

number $(b)$. The emissions of $\mathrm{OH}$ radicals can be used in order to identify regions of intense combustion. However, the applied chemiluminescence measurement technique only allows for the detection of excited $\mathrm{OH}$ molecules also referred to as $\mathrm{OH}^{*}$ whereas the results of the $\mathrm{CFD}$ simulation show the concentration of all present $\mathrm{OH}$ molecules. Thus, only a qualitative comparison can be made to validate the general shape of the flame.

Comparing the simulation with differential diffusion effects in the flame zone and the Abel transformed emission image, generally, a good agreement is achieved for the maximum radial spreading of the flame, although the flame is located sligthly further downstream than in the experiment. Likewise, a considerable $\mathrm{OH}$ concentration can be detected within the thin flame front just downstream of the injector which is thinner here than observed in the experiment. Applying the unity Lewis number assumption, however, the flame is much wider and also the maximum $\mathrm{OH}$ concentration is located further downstream but not close to the injector. Please note that the $\mathrm{OH}$ concentration predicted by the simulation is scaled with its maximum value for each case. An assessment of the total flame length is not possible as the optical access to the combustion chamber at the test rig was limited.

\section{CONCLUDING REMARKS}

Within the present work, fully consistent real gas models are established for the flow field and the combustion model of a CFD simulation based on the 
volume-corrected PR EOS. Special emphasis is placed on the analysis of the local structure of counterflow diffusion flames using the combustion simulation laboratory COSILAB as this structure provides the basis for the pre-integrated flamelet library applied along with the laminar flamelet combustion model. As application and for validation, the A-60 case tested at the Mascotte test rig V03 operated at ONERA $[37,38]$ is simulated using the commercial CFD solver ANSYS CFX. Here, hydrogen is injected at a supercritical state whereas for oxygen, the pressure is supercritical but the injection temperature is below its critical value.

Regarding the local structure of the counterflow diffusion flame, the species mass fraction profiles as well as the density and temperature distributions were found to be shifted towards the oxygen inlet when applying the real fluid modeling. Due to the high diffusivity of hydrogen this effect was enhanced when differential diffusion processes were included which also resulted in the increase in the flame thickness and the maximum flame temperature. Thus, the modeling of differential diffusion processes affects the flame structure significantly whereas the overall influence of the real gas EOS on the flame structure is limited as the oxygen heats up rapidly when entering the flame zone. The ideal gas EOS failed in predicting the density of oxygen at the transcritical injections conditions correctly. With increasing pressure, a decreasing flame thickness together with a higher maximum of the flame temperature was observed.

The RANS simulations were compared using different approaches of flow and combustion modeling. Due to an overestimation of the oxygen momentum flux at the inlet, the application of the ideal gas EOS for both the flow field and the flamelet model predicts a much too long flame. As long as the flamelet library is based on the unity Lewis number, similar temperature as well as $\mathrm{OH}$ radical distributions were found for a real gas modeling of the flow field regardless of whether real or ideal gas relations have been applied for the flamelet combustion model. Unrealistic results, however, were obtained including differential diffusion effects within the complete flamelet library. As reasons, the violation of the element conservation in the flamelets themselves as well as inaccuracies in the coupling of flamelet library and turbulent flow field could be identified. In order to still account for the high diffusivity of hydrogen, a mixed flamelet library, where differential diffusion was only considered in the flame zone, was generated and successfully applied to a CFD simulation. With respect to the flame shape and length, the validation against the experimentally measured $\mathrm{OH}^{*}$ concentration available for the A-60 case showed a much better agreement for the real gas simulation combined with the mixed flamelet library than for the unity Lewis number case.

Finally, the accurate prediction of the momentum flux at the inlet by applying proper real gas relations to the CFD modeling is of crucial importance in simulating gaseous hydrogen cryogenic liquid oxygen flames. Minor effects caused by real gas mixing rules as well as the modeling of the transport prop- 
erties could be observed for the one dimensional counterflow diffusion flame but their influence on the CFD simulation remains limited.

For future investigations, the simple RANS approach applying the $k-\epsilon$ turbulence model will be replaced by an LES formulation. Also, further improvement of the coupling procedure between the flamelet and the turbulent flow field is required.

\section{ACKNOWLEDGMENTS}

This work was performed within the collaborative research center SFB-TR 40 sponsored by the Deutsche Forschungsgemeinschaft (DFG). The authors gratefully acknowledge the support by the Rotexo Software team as well as the profund discussions with Dr. Frey and Dr. Ivancic from Astrium Space Transportation in Ottobrunn and Prof. Hasse from TU Bergakademie Freiberg.

\section{REFERENCES}

1. Peters, N. 2002. Turbulent combustion. Cambridge: Cambridge University Press.

2. Urzica, D., and E. Gutheil. 2009. Structures of counterflowing laminar methane/nitrogen/oxygen, methane/oxygen and methane/liquid oxygen counterflow flames for cryogenic conditions and elevated pressure. MCS. Corsica, France.

3. Pons, L., N. Darabiha, and S. Candel. 2008. Pressure effects on nonpremixed strained flames. Combust. Flame 152:218-29.

4. Pons, L., N. Darabiha, S. Candel, G. Ribert, and V. Yang. 2007. Mass transfer and combustion in transcritical non-premixed counterflows. 21st ICDERS. Portiers, France.

5. Balakrishnan, G., M. Smooke, and F. Williams. 1995. A numerical investigation of extinction and ignition limits in laminar nonpremixed counterflowing hydrogen-air streams for both elementary and reduced chemistry. Combust. Flame 102:329-40.

6. Poschner, M., and M. Pfitzner. 2008. Real gas CFD simulation of supercritical $\mathrm{H}_{2}-\mathrm{LOx}$ combustion in the Mascotte single-injector combustor using a commercial CFD code. AIAA Paper No. 2008-952.

7. Poschner, M., and M. Pfitzner. 2010. CFD-simulation of the injection and combustion of LOx and $\mathrm{H}_{2}$ at supercritical pressures. AIAA Paper No. 2010-1144.

8. Cutrone, L., P. De Palma, G. Pascazio, and M. Napolitano. 2010. A RANS flameletprogress-variable method for computing reacting flows of real-gas mixtures. Computers Fluids 39:485-98.

9. Kim, T., Y. Kim, and S. Kim. 2011. Numerical analysis of gaseous hydrogen/liquid oxygen flamelet at supercritical pressures. Int. J. Hydrogen Energy 23:6303-16.

10. Kim, T., Y. Kim, and S. K. Kim. 2011. Real-fluid flamelet modeling for gaseous hydrogen/cryogenic liquid oxygen jet flames at supercritical pressure. J. Supercritical Fluids 58:254-62. 
11. Barlow, R.S., G. J. Fiechtner, C. D. Carter, and J.-Y. Chen. 2000. Experiments on the scalar structure of turbulent $\mathrm{CO} / \mathrm{H}_{2} / \mathrm{N}_{2}$ jet flames. Combust. Flame 120:54969.

12. Ribert, G., N. Zong, V. Yang, L. Pons, N. Drabiha, and S. Candel. 2008. Counterflow diffusion flames of general fluids: Oxygen/hydrogen mixtures. Combust. Flame 154:319-30.

13. Zong, N., G. Ribert, and V. Yang. 2008. A flamelet approach for modeling of liquid oxygen $(\mathrm{LOx}) /$ methane flames at supercritical pressures. AIAA Paper No. 2008946.

14. Zong, N., and V. Yang. 2006. Cryogenic fluid jets and mixing layers in transcritical and supercritical environments. Combust. Sci. Technol. 178:193-227.

15. Schmitt, T., L. Selle, B. Cuenot, and T. Poinsot. 2009. Large-eddy simulation of transcritical flows. Comptes Rendus Mécanique 337(6-7):528-38.

16. Schmitt, T., L. Selle, A. Ruiz, and B. Cuenot. 2010. Large-eddy simulation of supercritical-pressure round jets. AIAA J. 48(9):2133-44.

17. Schmitt, T., Y. Mery, M. Boileau, and S. Candel. 2011. Large-eddy simulation of oxygen/methane flames under transcritical conditions. Proc. Combust. Inst. 33:1383-90.

18. Matsuyama, S., J. Shinjo, S. Ogawa, and Y. Mizobuchi. 2010. Large eddy simulation of $\mathrm{LOx} / \mathrm{GH}_{2}$ shear-coaxial jet flame at supercritical pressure. AIAA Paper No. 2010-208.

19. Jarczyk, M., and M. Pfitzner. 2012. Large eddy simulation of supercritical nitrogen jets. AIAA Paper No. 2012-1270.

20. Petit, X., G. Ribert, and P. Domingoz. 2012. Large eddy simulation of supercritical fluid injection. AIAA Paper No. 2012-1268.

21. Masquelet, M., N. Guézennec, and S. Menon. 2012. Numerical studies of mixing and flame-turbulence interactions in shear coaxial injector flows under transcritical conditions. AIAA Paper No. 2012-1269.

22. Okong'o, N., K. Harstad, and J. Bellan. 2002. Direct numerical simulations of $\mathrm{O}_{2} / \mathrm{H}_{2}$ temporal mixing layers under supercritical conditions. AIAA J. 40(5):91426.

23. Oefelein, J. 2006. Mixing and combustion of cryogenic oxygen-hydrogen shearcoaxial jet flames at supercritical pressure. Combust. Sci. Technol. 178:229-52.

24. COSILAB, Rotexo Software. 2011. Bochum.

25. Chapman, S., and T. Cowling. 1970. The mathematical theory of non-uniform gases. Cambridge: Cambridge University Press.

26. Kee, R, G. Dixon-Lewis, J. Warnatz, M. Coltrin, and J. Miller. 1986. A Fortran computer code package for the evaluation of gas-phase, multicomponent transport properties. SAND86-8246.

27. Pitsch, H., and N. Peters. 1998. A consistent flamelet formulation for non-premixed combustion considering differential diffusion effects. Combust. Flame 114(1-2):2640.

28. Burcat, A., and B. McBride. 1993. 1994 ideal gas thermodynamic data for combustion and air-pollution use. Technion Report TAE 697.

29. Peng, D., and P. Robinson. 1976. A new two-constant equation of state. Ind. Eng. Chem. Fundamentals 15:59-64. 
30. Harstad, G., R. Miller, and J. Bellan. 1997. Efficient high pressure equations of state. AIChE J. 43(6):703-23.

31. Poling, B., J. Prausnitz, and J. O'Connell. 2004. The properties of gases and liquids. McGraw-Hill.

32. Chung, T., M. Ajlan, L. Lee, and K. Starling. 1988 Generalized multiparameter correlation for nonpolar and polar fluid transport properties. Ind. Eng. Chem. Res. 27(4):671-79.

33. Fuller, E., P. Schettler, and J. Giddings. 1966. A new method for prediction of binary gas-phase diffusion coefficients. Ind. Eng. Chem. 58(5):19-27.

34. Takahashi, S. 1974. Preparation of a generalized chart for the diffusion coefficients of gases at high pressures. J. Chem. Eng. Japan 7(6):417-20.

35. CFX Software Package. Version 12.1. 2009. Germany: ANSYS.

36. Liu, F., H. Guo, G. J. Smallwood, Ö. L. Guelder, and M. D. Matovic. 2002. A robust and accurate algorithm of the beta-pdf integration. Int. J. Therm. Sci. 41:763-72.

37. Candel, S., G. Herding, R. Synder, P. Scouflaire, C. Rolon, L. Vingert, M. Habiballah, F. Grisch, M. Péalat, P. Bouchardy, D. Stepowski, A. Cessau, and P. Colin. 1998. Experimental investigation of shear coaxial cryogenic jet flames. J. Propul. Power 14(5):826-34.

38. Habiballah, M., and S. Zurbach. 2001. Test Case RCM-3, Mascotte single injector. 2nd Workshop (International) on Rocket Combustion Modeling.

39. NIST standard reference database number 69. 2005. Gaithersburg MD: National Institutes of Standards and Technology. 20899. http://webbook.nist.gov.

40. Ó Conaire, M., H. Curran, J. Simmie, W. Pitz, and C. Westbrook. 2004. A comprehensive modeling study of hydrogen oxidation. Int. J. Chem. Kinet. 36:603-22. 